\title{
Experimental studies of a hybrid car and electric car interference immunity
}

\author{
Vladimir Kozlovskiy ${ }^{1 *}$, Pavel Nikolaev ${ }^{2}$, Alexander Podgorniy ${ }^{1}$, Alexey Kritskiy ${ }^{1}$ and \\ Luiza Shamina ${ }^{3}$ \\ ${ }^{1}$ Samara State Technical University, Samara, Russia \\ 2 PJSC AVTOVAZ, Togliatty, Russia \\ ${ }^{3}$ National Technology Initiative Center for Advanced Manufacturing Technologies based on the \\ Institute of Advanced Manufacturing Technologies of Peter the Great St. Petersburg Polytechnic \\ University Polytechnicheskaya, 29, St.Petersburg, 195251, Russia
}

\begin{abstract}
This article covers a hybrid car interference immunity research. A combined unit-power plant vehicle prototype (a hybrid car) of a famous Russian brand is a subject of this research. Its configuration included a motor control center in boot of a car and a standard internal combustion engine control system (ICE) with upgraded software for joint operation of two power plants.
\end{abstract}

\section{Introduction}

The experiments showed three problems. The first one was when the charging of traction battery stopped in energy recuperation phase (figure 1) under narrow-band nonmodulated reaction. This discrepancy was characterized as a functional class $\mathrm{C}$, which means the charging continued with removal of above mentioned reaction.

The research showed that the discrepancy appeared in the range of frequencies from 80 to $1400 \mathrm{MHz}$.

\footnotetext{
*Corresponding author: kozlovsky vn@mail.ru
} 


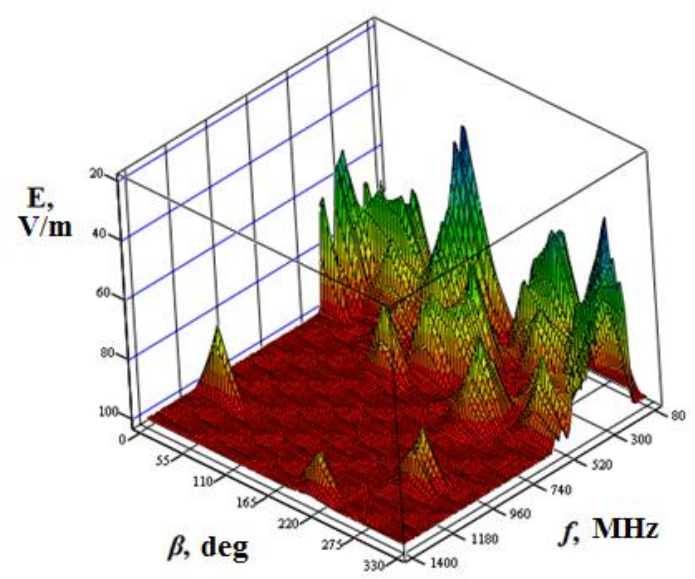

Fig. 1. The hybrid car energy recuperation interference immunity (traction battery charging stop)

\section{Materials, methods and results}

For $F_{\beta} \geq 0,3$ the range of frequencies was $90-600 \mathrm{MHz}$. Here we recorded $86,2 \%$ of discrepancies relative to the total number. The minimum discrepancy level of $28 \mathrm{v} / \mathrm{m}$ is related to this range of frequencies, recorded on the frequency $124 \mathrm{MHz}$ (Figure 2). For $F_{\beta} \geq$ 0,2 the range of frequencies was $90-640 \mathrm{MHz}$. It had 88,9\% of EMC problems. The data processing showed the maximum value of $\mathrm{Q}$ equals 28,3 .

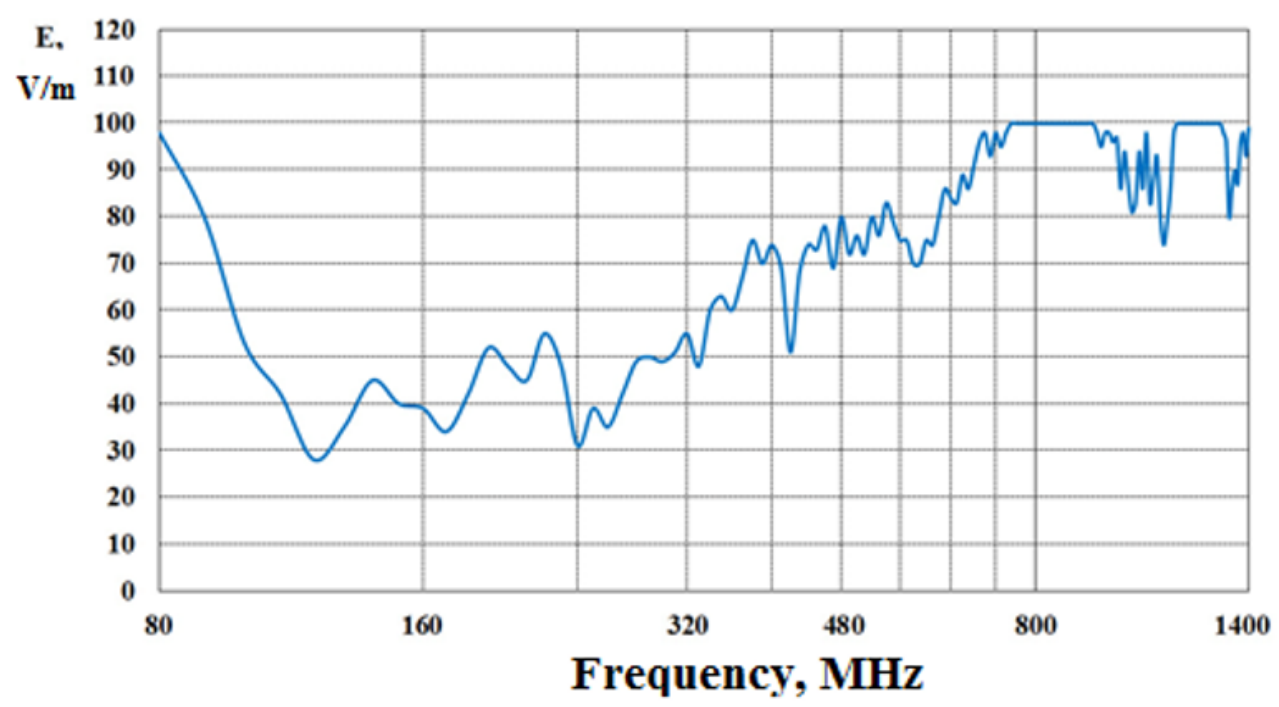

Fig. 2. The minimum values of the azimuthal projection of the hybrid car prototype energy recuperation interference immunity.

The comparison of results of standard and available penalty tests (figure 3) showed that in major range of frequencies the levels of electrical engineering system interference immunity are higher in standard front positioning, than in other azimuthal positioning angles of transport vehicle to a radiant. The minimum level of interference immunity is recordered under azimuthal angle of 120 degrees. 


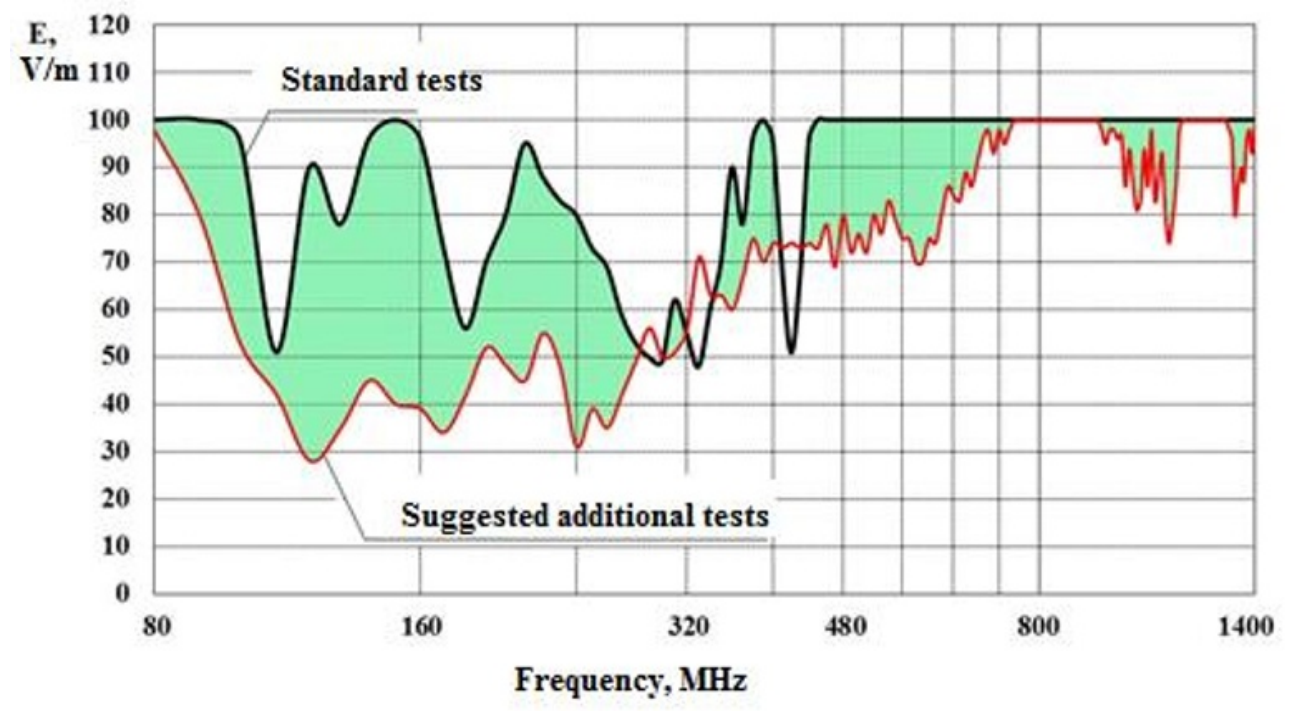

Fig. 3. The minimum values of the hybrid car prototype energy recuperation interference immunity in standard and available penalty tests.

The interference immunity by $100 \mathrm{v} / \mathrm{m}$ is reached by the optimization of controller grounding contour of the motor control center.

The second problem was when the internal combustion engine failed (Figure 4) with narrow-band amplitude modulation. When the traction battery was charged this discrepancy was characterized as a functional class $\mathrm{C}$, because the control was automatically shifted to the electric motor and the car kept moving. The shift to the electric traction was easy without any change while moving. As soon as electromagnetic effect was down the internal combustion engine started to work. If the traction battery was discharged, then the discrepancy was characterized as a functional class $\mathrm{D}$, because the car stopped. To resume its work, it was necessary to start the engine without any electromagnetic influence. 


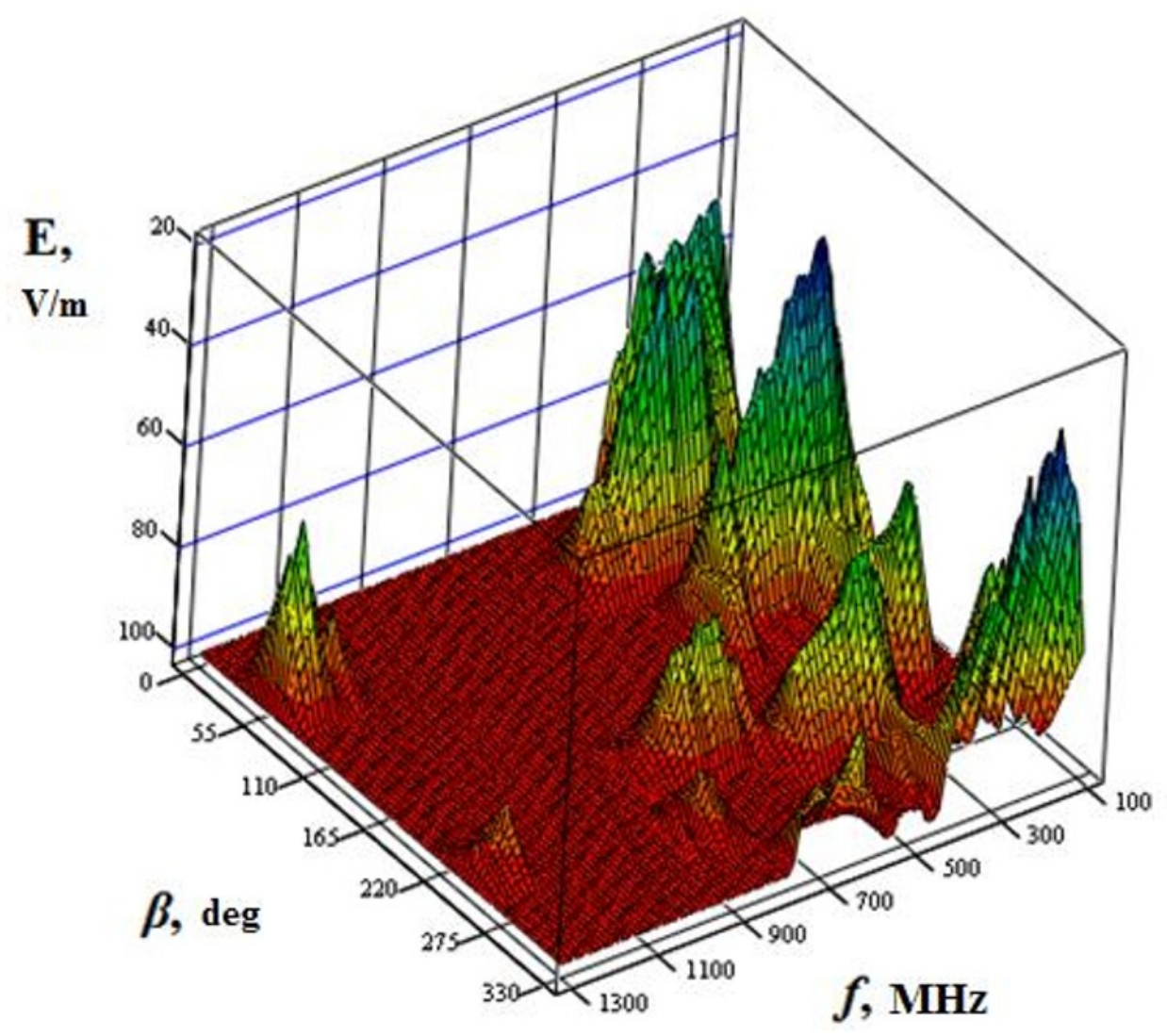

Fig. 4. The internal combustion engine control system of hybrid car prototype interference immunity (engine burnout).

For $F_{\beta} \geq 0,3$ the range of frequencies was $100-490 \mathrm{MHz}$. Here we recorded $74 \%$ of discrepancies relative to the total number. The minimum interference immunity level $25 \mathrm{v} / \mathrm{m}$ is related to this range, recorded on the frequency $201 \mathrm{MHz}$ (Figure 5). For $F_{\beta} \geq 0,2$ the range of frequencies was $98-600 \mathrm{MHz}$. It had $81,4 \%$ of EMC problems.For $F_{\beta} \geq 0,3$ the range of frequencies was $100-490 \mathrm{MHz}$. Here we recorded $74 \%$ of discrepancies relative to the total number. The minimum interference immunity level $25 \mathrm{v} / \mathrm{m}$ is related to this range, recorded on the frequency $201 \mathrm{MHz}$ (Figure 5). For $F_{\beta} \geq 0,2$ the range of frequencies was $98-600$ MHz. It had $81,4 \%$ of EMC problems. 


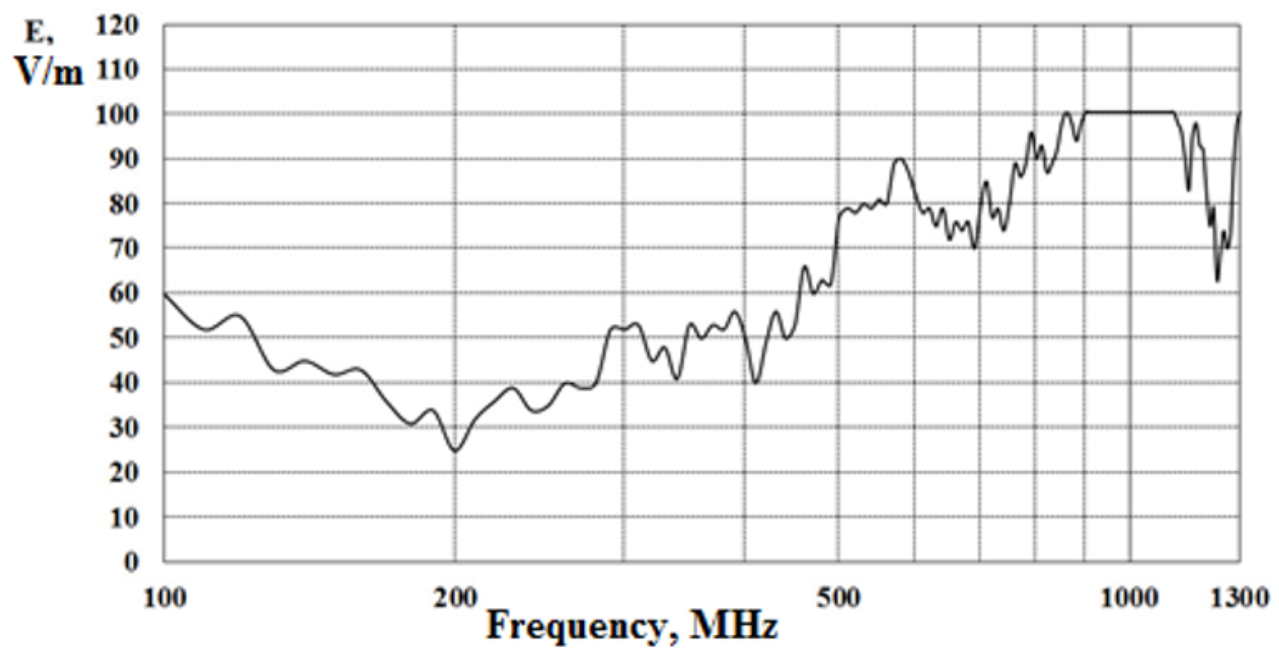

Fig. 5. The minimum value of azimuthal projections of the internal combustion engine control system of hybrid car prototype interference immunity.

The data processing showed the maximum value of $Q$ equals 33,8 .

The comparison of results of standard and available penalty tests (figure 6) showed that in major range of frequencies the levels of electrical engineering system interference immunity are higher in standard front positioning, than in other azimuthal positioning angles of transport vehicle to a radiant. The minimum level of interference immunity is recordered under azimuthal angle of 120 degrees.

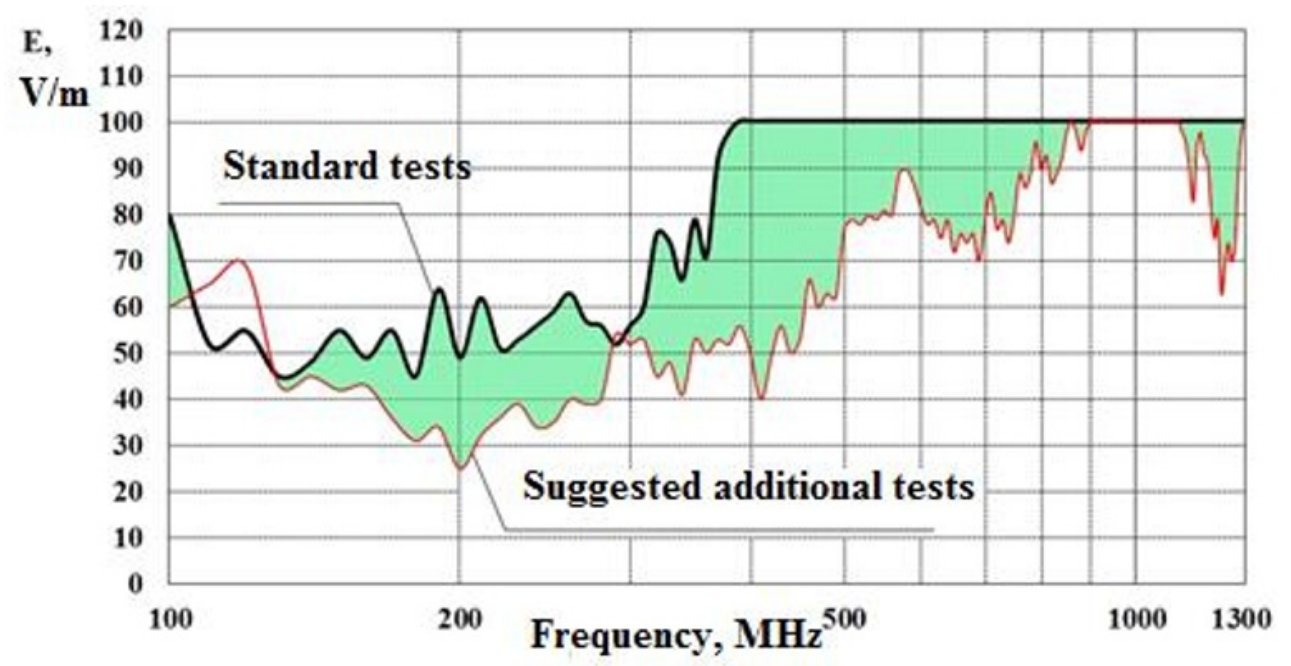

Fig. 6. The minimum values of the internal combustion engine control system hybrid car prototype interference immunity in standard and available penalty tests.

The interference immunity by $100 \mathrm{v} / \mathrm{m}$ is reached by the improvement of filtration of controller supply networks of the internal combustion engine control center.

The third problem of the car with a combined power facility has occurred with electric engine burnout (Figure 7) under impulse electro-magnetic emission. This discrepancy was characterized as a functional class E, because eventhough the control was automatically 
shifted to the internal combustion engine and the car kept moving, the electric motor itself didn't start to operate. In order a car to operate on electric traction battery it was necessary to switch on and off the electric battery when the electromagnetic effect was not available.

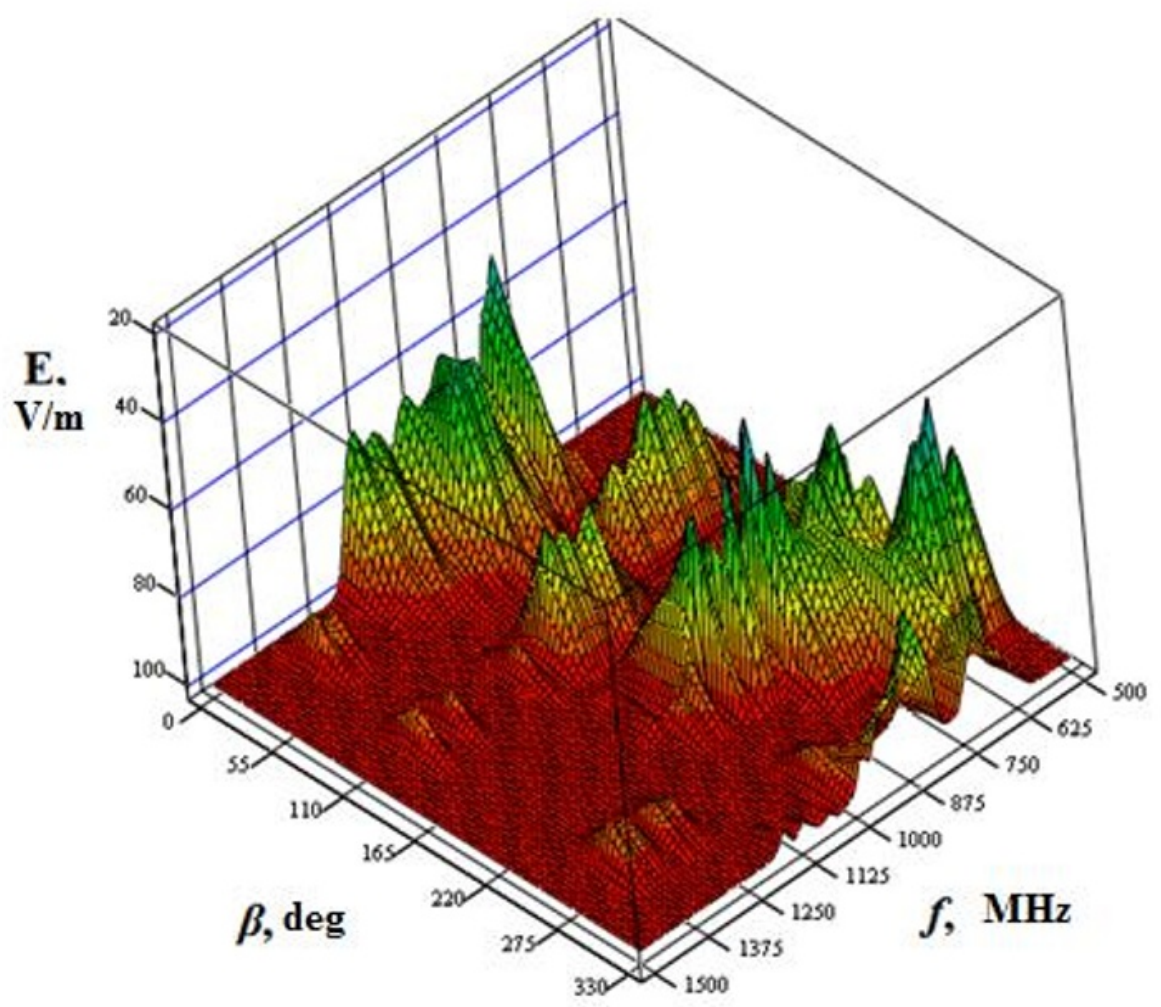

Fig. 7. The electric engine control system of hybrid car prototype interference immunity (electric engine burnout under the impulse electromagnetic emission).

The research showed that the discrepancy appeared in the range of frequencies from 500 to $1400 \mathrm{MHz}$.

For $F_{\beta} \geq 0,3$ the range of frequencies was $560-1160 \mathrm{MHz}$. Here we recorded $86,9 \%$ of discrepancies relative to the total number. The minimum interference immunity level $43 \mathrm{v} / \mathrm{m}$ is related to this range, recorded on the frequency $597 \mathrm{MHz}$ (Figure 8). For $F_{\beta} \geq 0,2$ the range of frequencies was $540-1360 \mathrm{MHz}$. It had 95,6\% of EMC problems.

The data processing showed the maximum value of $Q$ equals 32,4. 


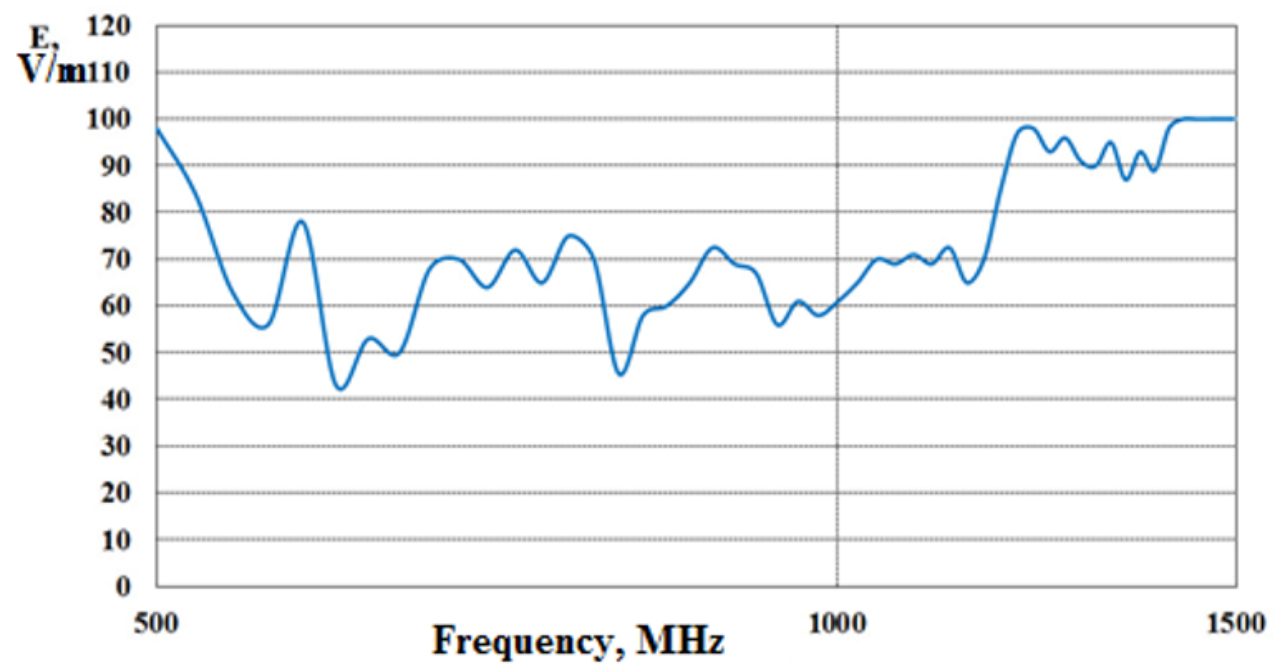

Fig. 8. The minimum value of azimuthal projections of the electric engine control system of hybrid car prototype interference immunity.

The comparison of results of standard and available penalty tests (figure 9) showed that in major range of frequencies the levels of electrical engineering system interference immunity are higher in standard front positioning, than in other azimuthal positioning angles of transport vehicle to a radiant. The minimum level of interference immunity is recordered under azimuthal angle of 270 degrees.

The research showed that the discrepancy appeared in the range of frequencies of GSM standard. This confirms that the transport vehicle could be sensitive to a cellular network.

The research of discrepancy showed that it happened because of hangup of motor control center microprocessor set. The interference immunity by $100 \mathrm{v} / \mathrm{m}$ is reached by using a watch dog timer, which in case of microprocessor hang up would reboot it in $20 \mathrm{~ms}$.

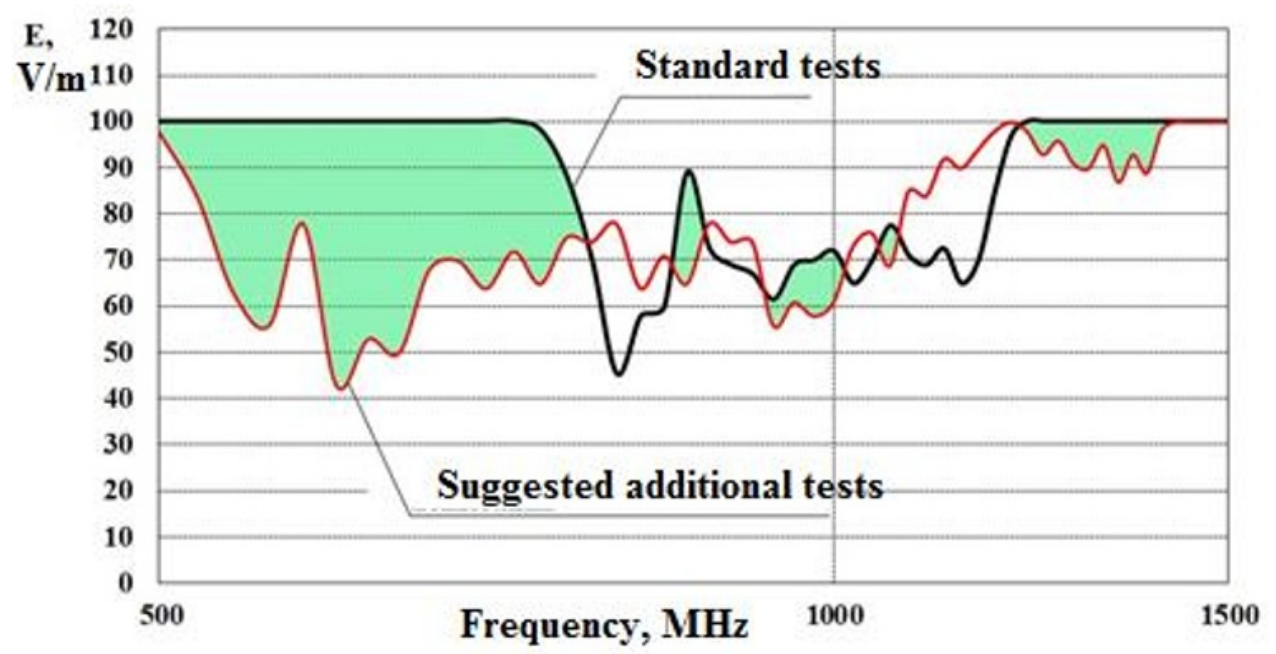

Fig. 9. The minimum values of the electric engine control system hybrid car prototype interference immunity in standard and available penalty tests. 
The research is of electric car interference immunity. An electric engine car of an indicated power of $30 \mathrm{~kW}$ of a foreign brand is a subject of this research.

The research of electric car interference immunity revealed the discrepancy which occurred when the electric engine has burned out (Figure 10) and was characterized as a functional class D. To start the electric car it was necessary to switch on and off the button of onboard electric system.

The research showed that the discrepancy appeared in the range of frequencies from 110 to $490 \mathrm{MHz}$ under the narrowband nonmodulated electromagnetic emission.

The results analysis showed that for $F_{\beta} \geq 0,3$ the range of frequencies was $130-440$ MHz. Here we recorded $95,6 \%$ of discrepancies relative to the total number. The minimum interference immunity level $49 \mathrm{v} / \mathrm{m}$ is related to this range, recorded on the frequency 343 $\mathrm{MHz}$ (Figure 11). For $F_{\beta} \geq 0,2$ the range of frequencies was $120-450 \mathrm{MHz}$. It had $97,8 \%$ of EMC problems.

The data processing showed the maximum value of $Q$ equals 24,6 .

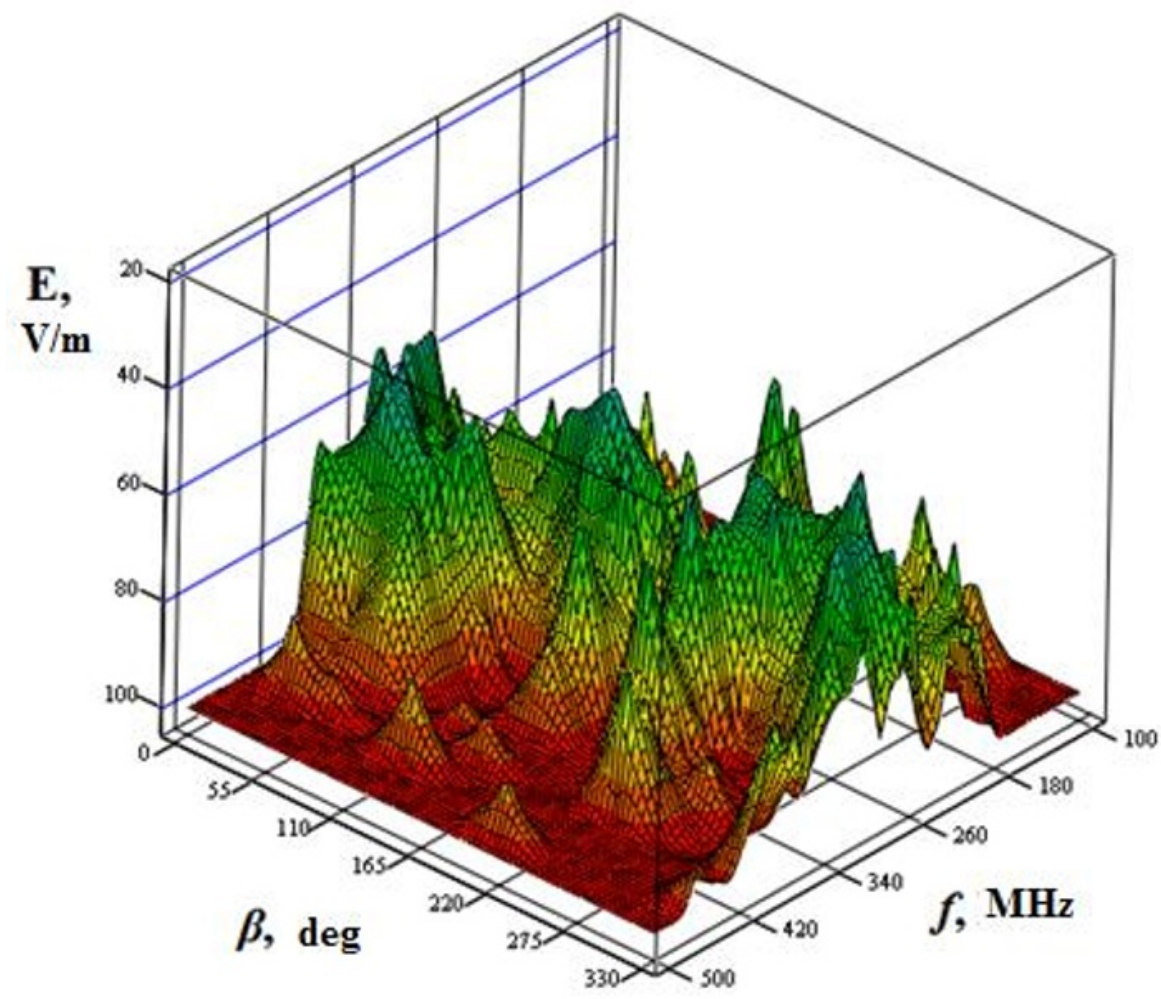

Fig. 10. The electric car interference immunity.

The comparison of results of standard and available penalty tests (Figure 12) showed that in major range of frequencies the levels of electrical engineering system interference immunity are higher in standard front positioning, than in other azimuthal positioning angles of transport vehicle to a radiant. The minimum level of interference immunity is recordered under azimuthal angle of 30 degrees.

Since we tested a foreign electric car, it was complicated to study the reasons of discrepancy in detail and to find out the solution to increase the interference immunity. 


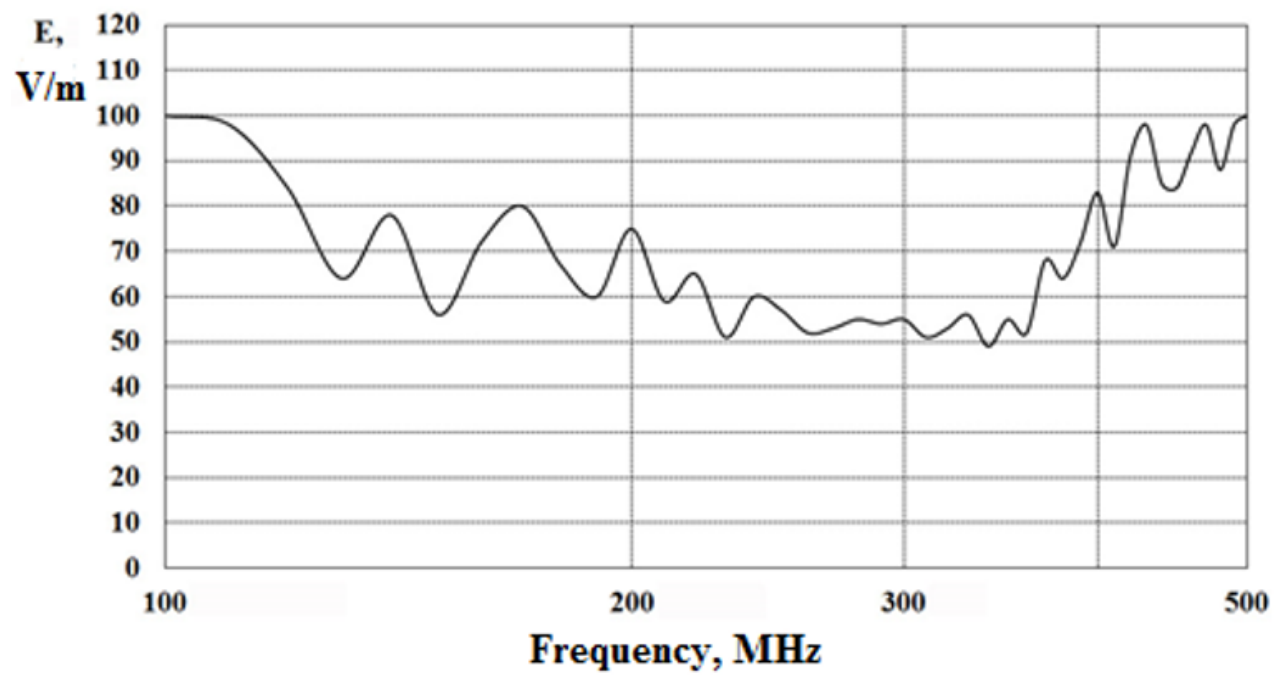

Fig. 11. The minimum values of azimuthal projections of the electric car interference immunity.

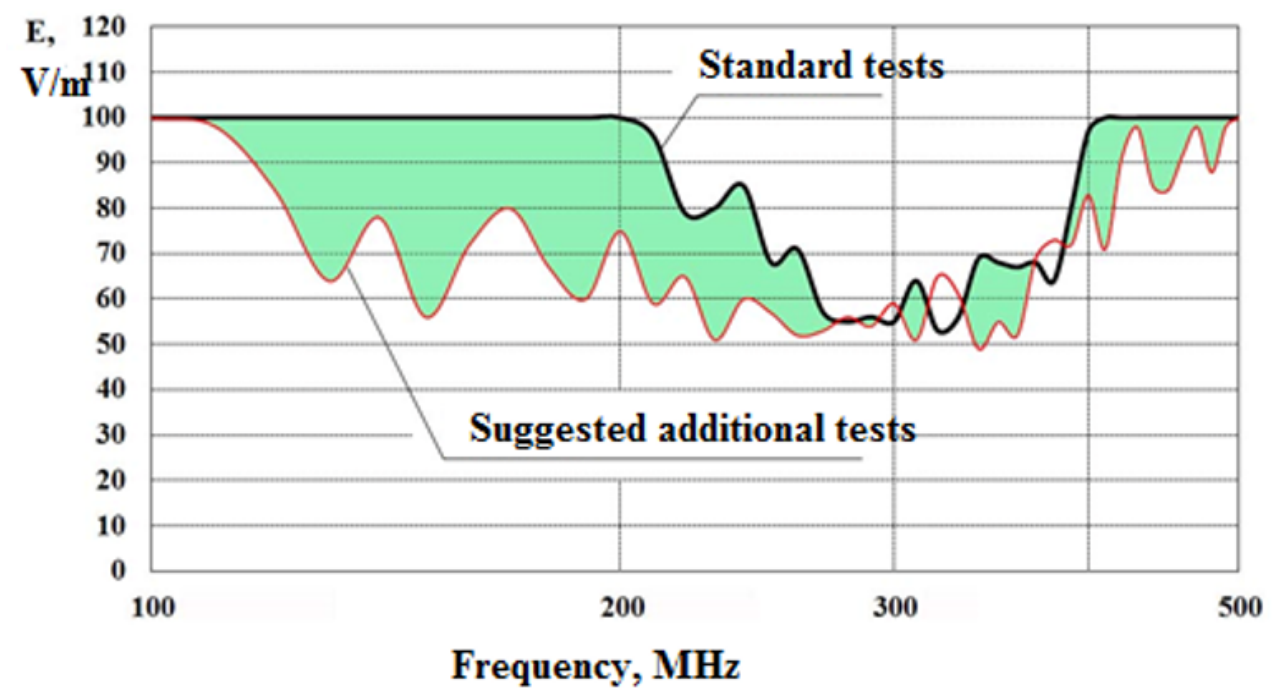

Fig. 12. The minimum values of the electric car interference immunity in standard and available penalty tests.

Carrying out such calculations is a lot of work, at the beginning of which all the necessary information is collected on a radiation-hazardous object, as well as possible accident scenarios are identified, which are subsequently calculated in terms of consequences. After that, the identified scenarios are calculated and the maximum consequences from them are determined, then a decision is made on categorizing the radiation-hazardous object and choosing measures to improve the safety of personnel and the population, as well as recommendations for creating reserves of resources to eliminate the consequences of these accidents.

Usually such calculations can be divided into four interrelated parts resulting from each other, namely: determination of the release of radionuclide into the air of premises and contamination of these premises, pollution outflow from the building and pollution of the 
environment, calculation of the dose received by the facility's personnel, of these accidents (Figure 13).

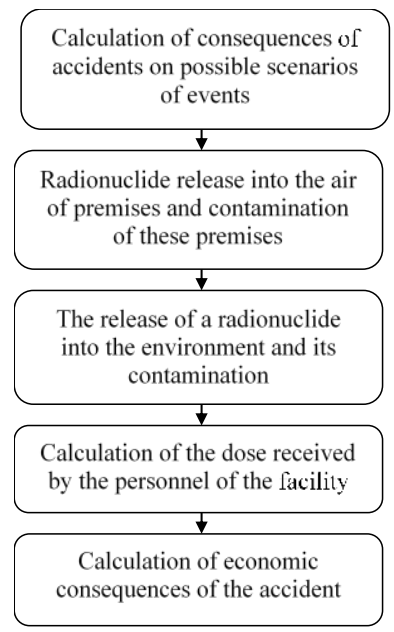

Fig. 13. The scheme for calculating the consequences of radiation accidents.

But first of all, we should be interested in the component connected directly with the person - participant in this incident, since human life and health is the highest value that exists. Therefore, we also need to find out what the maximum dose can get a person - a participant in this incident at a radiation-hazardous facility.

Calculation of human exposure includes two equal components, namely: the dose of external irradiation (through the skin) and the dose of internal irradiation, the latter in turn also divided into two components: the dose for inhalation and dose for ingestion (Figure 14 ).

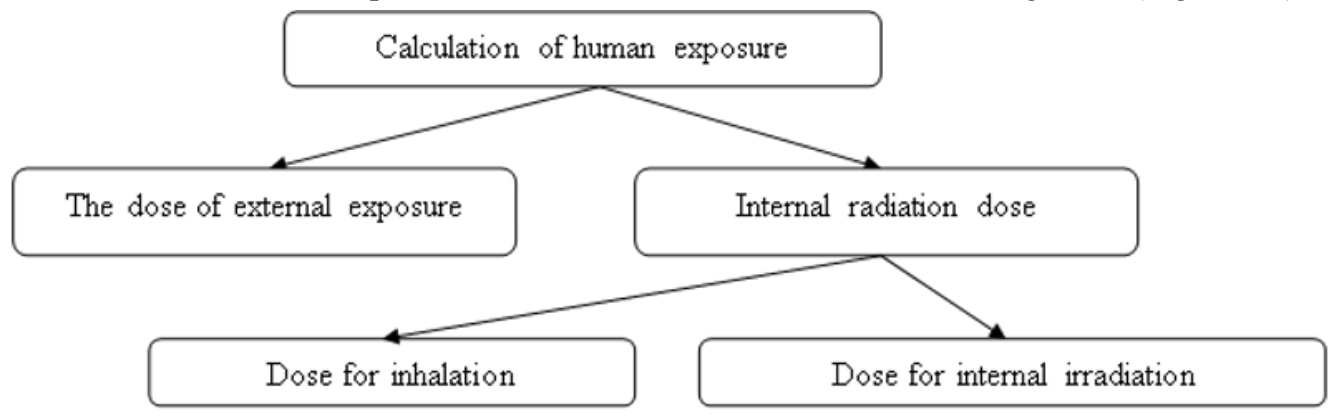

Fig. 14. Scheme of calculation of human exposure.

Calculation of human exposure can be done using the following formulas [10-12]:

The dose of external irradiation $\left(E_{\text {ext }}\right.$, Sievert $\left.\left(S_{\mathrm{v}}\right)\right)$ of the formula:

$$
E_{\text {ext }}=A_{\mathrm{v}} \cdot B \cdot t
$$

where: $A_{\mathrm{v}}$ - surface volumetric activity of the radionuclide on the axis of the torch at a distance of $\mathrm{x}$ meters from the source (in the direction of the wind), $\mathrm{Bk} / \mathrm{m}^{3} ; B$ - dose coefficient for external exposure, taking into account the type of particles that irradiation occurs (gamma, beta or joint), $\mathrm{Sv}^{\cdot} \mathrm{m}^{3} / \mathrm{Bk}$; $t$ - duration of impact of the radioactive cloud, sec.

For internal irradiation with an inhalation intake of a radionuclide, the effective dose $\left(\mathrm{E}_{\text {ing, }}\right.$, $\mathrm{S}_{\mathrm{v}}$ ) according to the formula:

$$
E_{\text {ing }}=A_{\mathrm{v}} \cdot B_{\text {ing }} \cdot t_{\text {eff, }}
$$


where: $A_{\mathrm{v}}$ - volume activity of the radionuclide in air, $\mathrm{Bk} / \mathrm{m}^{3} ; B_{\text {ing }}$ - dose rate of internal exposure when inhaled radionuclide intake into the human body, $\mathrm{S}_{\mathrm{v}} \cdot \mathrm{m}^{3} / \mathrm{Bk} \mathrm{S} ; t_{\text {eff }}-$ is the effective time of exposure of the radionuclide radionuclide to the recipient, sec.

For internal irradiation with ingestion of the radionuclide, the effective dose $\left(E_{\mathrm{zag}}, S_{\mathrm{v}}\right)$ according to the formula:

$$
E_{\mathrm{zag}}=A_{\mathrm{m}} \cdot B_{\mathrm{zag}} \cdot t_{\mathrm{eff}}
$$

where: $A_{\mathrm{m}}$ is the activity of a unit mass of the swallowed substance, $\mathrm{Bk} / \mathrm{kg} ; B_{\mathrm{zag}}-\operatorname{dose}$ coefficient of internal irradiation with ingestion of a radionuclide into the human body, $S_{\mathrm{v}} \cdot \mathrm{m}^{3} / \mathrm{Bk} \cdot \mathrm{s} ; t_{\mathrm{eff}}-$ is the effective time of exposure of the radionuclide ingestion.

Usually, when calculating these impacts on the person of the consequences of an incident at the site, a number of restrictions are imposed on the course of the scenario of the development of the incident, most often one of them is the limitation of the time of exposure of the person to polluted air $[13,14]$. This restriction is caused by the fact that it is considered that the incident with the source is detected rather quickly, after that an alarm is given and personnel are evacuated from the danger zone. With such a development of the situation, this restriction has the right to its existence, especially when it comes to fairly powerful sources of radiation, but with the development of science and technology, weaker sources became widely used too: for example, in medicine, the so-called radiopharmaceuticals. The peculiarity of the incidents, for example, in the spilled poisons, with such drugs can be that often, according to the instructions, the collection of the spilled product, and, consequently, the elimination of the consequences of the incident, is placed directly on the medical personnel working with these radiopharmaceuticals. Accordingly, in fulfillment of their job descriptions, these workers can not be evacuated, and the overlapping limitation of exposure (usually one hour) is not correct, because in this case, during the impact will also include the time to eliminate the incident, which can significantly exceed the value of one hour.

Another problem when calculating the consequences of accidents with radiation sources is the determination of the concentration of radionuclides in the interior of the rooms where the accident occurred. For a basis of calculations we take the formula:

$$
C_{\mathrm{m}}=A_{\mathrm{m}} / V_{\mathrm{o}}=Q \cdot[1-\exp (-n \cdot t)] / n \cdot V_{\mathrm{o}}
$$

where $C_{\mathrm{m}}$ is the concentration of the radionuclide in the air; $A_{\mathrm{m}}$ - the maximum activity of the radionuclide in the room air at time t, $\mathrm{Bk} ; Q$ - the intensity of the output of the RS from the source (power of the source of the RS), Bk / h; $n$ - frequency of air exchange, hour ${ }^{-1} ; t$ - time of action of the source, hour; $V_{\mathrm{o}}$ is the volume of the room, $\mathrm{m}^{3}$.

\section{Discussion and results}

It is usually assumed that the radionuclide spreads throughout the volume of the room where the accident took place evenly, and then the concentration is calculated according to simple formulas taking into account the room volume and the frequency of air exchange in the rooms. And if the enterprise has several rooms that are not isolated from each other the assumption is often used that the distribution of activity between the premises is proportional to their volumes. The actual calculation of the concentration is not done, for the reason that at the moment there is no methodology for such calculations, and obtaining data through experiments is not appropriate, since such experiments will have to be carried out for each individual case separately, but not simply to conduct, and also create an experimental model of premises for which it is necessary to know the concentration of radionuclides (taking into account such parameters as: arrangement of equipment in the room, meteorological conditions.

Another "money" issue for the company is the insurance amount and insurance premiums under the insurance contract. A more accurate assessment of the received damage from the 
incident, in turn, can affect the insurance amount of the hazardous production facility, and immediately in two directions: on the one hand, in the case of a more accurate calculation of the consequences (for example, taking into account the actual concentration of radioactive substances in the room) Accidents, together with the impact on the person participating in the accident, may decrease, which will lead to a reduction in the insurance amount for the enterprise, which will entail a reduction in insurance premiums, paying and, in the end, a reduction in the company's fixed costs, and on the other hand, if the scale of the consequences of the accident increases, including the impact on the person participating in the accident, will lead to an increase in insurance premiums, but in this case the amount of money will also increase, from which compensation will be paid to the victims, and accordingly the enterprise can be freed from material losses related to the payment of damages that the insured sum could not cover (counted "in the old way" more is not exact and, accordingly, it turned out to be less real). [15-17]

One of the ways to solve the questions posed is to translate these calculations into automated calculations using special software.

Using this program allows improving the quality and accuracy of calculations: 10 specialists were offered one object for calculation, the result of calculation is presented in the table 1.

Table 1. Setting Word's margins.

\begin{tabular}{|c|c|c|}
\hline Calculation made & $\begin{array}{l}\text { Bulk activity of the radionuclide } \\
\qquad\left(C_{\mathrm{m}}\right), \mathrm{Bk} / \mathrm{m}^{3}\end{array}$ & $\begin{array}{c}D_{\text {ind, }} \text { for staff, } \\
\mu \mathrm{Sv}\end{array}$ \\
\hline specialist 1 & $1,76 \times 10^{3}$ & 27,9 \\
\hline specialist 2 & $1,8 \times 10^{3}$ & 29,1 \\
\hline specialist 3 & $3,2 \times 10^{3}$ & 51,42 \\
\hline specialist 4 & $1,71 \times 10^{3}$ & 25,6 \\
\hline specialist 5 & $1,74 \times 10^{3}$ & 27,63 \\
\hline specialist 6 & $1,7 \times 10^{3}$ & 27,1 \\
\hline specialist 7 & $1,69 \times 10^{3}$ & 26,5 \\
\hline specialist 8 & $1,73 \times 10^{3}$ & 28,42 \\
\hline specialist 9 & $1,75 \times 10^{3}$ & 27,42 \\
\hline specialist 10 & $1,72 \times 10^{3}$ & 27,2 \\
\hline Software & $1,7431 \times 10^{3}$ & 27,42 \\
\hline
\end{tabular}

The strong difference between the results from the total mass in the calculation of Specialist No. 3 is caused, as shown by the check, that the expert did not correctly select one of the coefficients of the characteristic radioactive substance. Accordingly, the application of this program will avoid these errors. Plus, the application of the program makes it possible to improve the accuracy of the calculations carried out by increasing the number of decimal places, which will allow you to adjust the necessary funds that the company pays in the event of an accident.

There is also an economic effect from the application of this program: due to the use of the program, the time of direct calculations is reduced several times, which, according to experts, will reduce the cost of the work done by about $10-15 \%$.

\section{Conclusion}

It is clear that modern methods for calculating the consequences of radiation accidents, along with these problematic issues, have a number of other shortcomings that affect the accuracy of calculations, which in turn affects the assessment of the impact of the accident, primarily in terms of calculating the dose, received by the staff. Elimination of these shortcomings and 
should be set as one of the main directions in ensuring security when using radioactive substances in the national economy.

\section{Acknowledgment}

The research is funded by the Russian Federation President Grant NSH2515.2020.8

\section{References}

1. Normy radiacionnoj bezopasnosti (NRB-99/2009): Gigienicheskie normativy.- M.: Minzdrav Rossii (2009)

2. S. Efremov, Y. Logvinova, I. Russkova, M. Polyukhovich, A method for assessing climatic parameters working at low temperatures as an element of technological safety, Paper presented at the IOP Conference Series: Earth and Environmental Science, 539(1) doi:10.1088/1755-1315/539/1/012031(2020)

3. I. V. Aladyshkin, S. V. Kulik, S. V. Efremov, The conceptual bases of the scientific direction "technosphere safety", Paper presented at the IOP Conference Series: Earth and Environmental Science, , 459(2) doi:10.1088/1755-1315/459/2/022029 (2020)

4. A. Byzov, A. Pak, D. Kuznetsova, G. Ostapenko, Analysis of the statistical correlation between the estimated value of individual risk and the hazard class of a hazardous production facility in the russian federation, Paper presented at the E3S Web of Conferences, 140 doi:10.1051/e3sconf/201914008004 (2019)

5. M. Borisova, A. Byzov, S. Efremov, Assessment of the maximum possible number of victims of accidents at hazardous production facilities for insurance purposes, Paper presented at the IOP Conference Series: Materials Science and Engineering, 666(1) doi:10.1088/1757-899X/666/1/012096 (2019)

6. A. P. Byzov, A. I. Shershneva, M. A. Ens, Assessment methodology for personal risk assessment in the field of waste storage, Paper presented at the Proceedings of the 2018 IEEE International Conference "Management of Municipal Waste as an Important Factor of Sustainable Urban Development", WASTE 2018, 49-51. doi:10.1109/WASTE.2018.8554146 (2018)

7. M. Avdeeva, A. Byzov, K. Smyshlyaeva, N. Leonova, Assessment of the fire situation of a certain building using fenix + , doi:10.1007/978-3-030-57453-6_35 (2021)

8. A.S. Usy`pko, O.N. Terent`ev, Raschet ushherba ot radiaczionny `kh avarij pri ispol zovanii radioaktivny 'kh veshhestv na ob 'ektakh narodnogo khozyajstva, $\mathrm{V}$ sbornike: Nedelya nauki SPbGPU. materialy’ XLII nauchno-prakticheskoj konferenczii c mezhdunarodny`m uchastiem, S. 107-109 (2014)

9. A.S. Usy`pko, O.N. Terent `ev, Oczenka professional 'ny 'kh riskov dlya sotrudnikov radiaczionno-opasny kh ob 'ektov, V sbornike: Nauchny`j forum s mezhdunarodny`m uchastiem "Nedelya nauki SPbPU". Materialy` nauchno-prakticheskoj konferenczii, S. 227-230 (2015)

10. Mezhotraslevaya metodika rascheta ekonomicheskogo ushcherba ot radiacionnyh avarij pri ispol'zovanii radioaktivnyh veshchestv v narodnom hozyajstve, OOO «REScentr», reg.№ R-03/98, Sankt-Peterburg (2006)

11. Vremennaya tipovaya metodika opredeleniya ekonomicheskoj effektivnosti osushchestvleniya prirodoohrannyh meropriyatij i ocenki ekonomicheskogo ushcherba, prichinyaemogo narodnomu hozyajstvu zagryazneniem okruzhayushchej sredy (utv. 
28.10.83 g. postanovleniem Gosplana SSSR, Gosstroya SSSR i Prezidiuma Akademii nauk SSSR za № 254/284/134) (1983)

12. A.D. Zimon, V.K. Pikalov, Dezaktivaciya, M., IzdAT (1994)

13. Radiacionnaya zashchita, Publikaciya MKRZ № 37, M., Atomizdat (1985)

14. US Nuclear Regulatory Commission, final environmental statement on the transportation of Radioactive material by air and other modes, NUREG- 0170, v.1., Nuclear Regulatory Commission, Washington D.C. 2055, December, (1977)

15. J. I. Idrisova, T. T. Kaverzneva, N. V. Rumyantseva, I. L. Skripnik, Neural network modeling of safety system for construction equipment operation in permafrost zone Paper presented at the IOP Conference Series: Earth and Environmental Science, 302(1) doi:10.1088/1755-1315/302/1/012128 (2019)

16. J.I. Idrisova, V.N. Myasnikov, A.I. Uljanov, N.V. Belina, Increasing the efficiency of labor protection in the enterprise, Paper presented at the International Conference on Information Networking, 2018-January 586-588 (2018).

17. T. Kaverzneva, N. Rumyantseva, A. Uljanov, N. Belina, Use of the logical-statistical model as a procedure for assessing occupational risks in the OSH management, Paper presented at the IOP Conference Series: Materials Science and Engineering, 666(1) doi:10.1088/1757-899X/666/1/012091 (2019) 